\title{
28 Research Square \\ Undernutrition in pregnant sheep alters the behavior of ruminal microbiota and epithelium
}

\author{
Yanfeng Xue \\ Limei Lin \\ Fan $\mathrm{Hu}$ \\ Weiyun Zhu \\ Shengyong Mao
}

\section{Video Byte}

Keywords: Microbiome, Ruminal homeostasis, Ruminal microbiota, epithelium, Energy metabolism, Signal transduction, Severe feed restriction, ruminant, nutrition, production animals, sheep, pregnancy, rumen, protein synthesis, carbohydrate metabolism

Posted Date: November 12th, 2020

DOI: https://doi.org/10.21203/rs.3.rs-106707/v1

License: (c) (i) This work is licensed under a Creative Commons Attribution 4.0 International License. Read Full License 


\section{Abstract}

Undernourishment or undernutrition can be caused by a lack of food or a high energy demand, such as during pregnancy and lactation. Undernutrition in production animals disrupts metabolic homeostasis and causes serious health problems, including maternal metabolic disorders and stillbirth. Many production animals are ruminants, named for their unique digestive organ, the rumen, which houses a diverse anaerobic microbiome. The ruminal microbiome allows the host to break down hard-to-digest plant carbohydrates and produce protein that the host later absorbs. But little is known about the effects of undernutrition on the host-microbiome interaction in ruminants. A recent study investigated changes in the ruminal microbiome and epithelium in undernourished pregnant sheep. During undernutrition, the bacterial genes involved in the digestion of carbohydrates and protein synthesis were downregulated. This meant less energy and protein was available to the host and critical signaling pathways were inhibited. Ultimately, these changes repressed the growth of epithelial cells, leading to shorter, thinner papillae. These results are an early look into systemic microbiota-host interactions during malnutrition and serve as a starting point to develop nutritional strategies to reduce energy shortage in pregnant ruminants. 